\title{
PFPRINTE

\section{4) Perfil das publicações sobre nutrição e idosos no Brasil: uma revisão sistemática}

\author{
Renata Breda Martins'; Valéria Baccarin laniski'; Raquel Seibel; \\ Analie Nunes Couto'; Leticia Mazocco'; Maria Luiza Freitas Annes'; \\ Melissa Côrtes da Rosa ${ }^{1}$; Carla Helena Augustin Schwanke ${ }^{2}$
}

\section{Resumo}

Introdução: O crescimento da população idosa tem despertado interesse no desenvolvimento de pesquisas que envolvam este grupo etário. Uma das temáticas investigadas é a nutrição, devido ao seu impacto no envelhecimento normal e patológico. Objetivo: deste trabalho foi descrever o perfil das publicações brasileiras sobre a temática nutrição e idosos. Métodos: Realizou-se uma revisão sistemática através da busca de artigos na base de dados eletrônica LILACS, realizada em maio de 2018, sem limite em relação ao ano da publicação. Foram utilizados os descritores "nutrição" e "idoso" e os filtros "idioma", "idade" e país". Na identificação dos assuntos investigados cada artigo poderia contemplar mais de um assunto. Resultados: Foram identificados 115 artigos. Dezessete artigos foram excluídos por não atenderem aos critérios de inclusão ou não estarem disponíveis na íntegra. Foram analisados 98 artigos, sendo a maioria estudos originais (96,0\%), com delineamento transversal (80,6\%), envolvendo homens e mulheres concomitantemente $(83,7 \%)$. Quanto ao período, $67,3 \%$ artigos ( $n=66)$ foram publicados entre $2010-2017,31,6 \%(n=31)$ entre $2000-2009$ e $1,1 \%(n=1)$ entre 1990-1999. Foram identificados 14 assuntos investigados, sendo os três mais frequentes, "estado nutricional" 51,0\% ( $n=50)$, "consumo alimentar" 29,5\% ( $n=29)$ e "antropometria" 12,2\% ( $n=12)$, e os menos frequentes "fragilidade" 1,0\% (n= 1), "imagem corporal" 1,0\% $(n=1)$ e "rotulagem de alimentos" $1,0 \%(n=1)$. Conclusão: Observou-se maior frequência de artigos originais, com delineamento transversal, publicados no período 2010-2017 e que abordaram os assuntos estado nutricional, consumo alimentar e antropometria.

Palavras-chave: Idoso. Envelhecimento. Nutrição. Comunicação acadêmica.

1 Programa de Pós-graduação em Gerontologia Biomédica Pontifícia Universidade Católica do Rio Grande do Sul (PUCRS), Escola de Medicina. Endereço para correspondência: Av. Ipiranga, 6681, prédio 81, 7º andar, sala 703, Bairro Partenon, Porto Alegre/RS-Brasil, CEP 90619-900. E-mails (na ordem em que aparecem): nutri.renatamartins@ gmail.com; valeriaianiski@gmail.com; raquelseibel@hotmail.com; analiecouto@hotmail.com; lety.mazocco@gmail. com; maluannes@hotmail.com; nutrimel@gmail.com

2 Professora do Programa de Pós-graduação em Gerontologia Biomédica da PUCRS, Escola de Medicina. E-mail: schwanke@pucrs.br 


\section{Introdução}

O crescimento da população idosa tem despertado interesse no desenvolvimento de pesquisas que envolvam este grupo etário. Uma das temáticas investigadas é a nutrição, devido ao seu impacto no envelhecimento normal e patológico.

\section{Objetivo}

O objetivo deste trabalho foi descrever o perfil das publicações brasileiras sobre a temática nutrição e idosos. Métodos: Realizou-se uma revisão sistemática através da busca de artigos na base de dados eletrônica $L I L A C S$, realizada em maio de 2018, sem limite em relação ao ano da publicação. Foram utilizados os descritores "nutrição" e "idoso" e os filtros "idioma", "idade" e país". Na identificação dos assuntos investigados cada artigo poderia contemplar mais de um assunto.

\section{Resultados}

Foram identificados 115 artigos. Dezessete artigos foram excluídos por não atenderem aos critérios de inclusão ou não estarem disponíveis na íntegra. Foram analisados 98 artigos, sendo a maioria estudos originais $(96,0 \%)$, com delineamento transversal $(80,6 \%)$, envolvendo homens e mulheres concomitantemente (83,7\%). Quanto ao período, 67,3\% artigos $(\mathrm{n}=66)$ foram publicados entre 2010-2017, 31,6\% ( $\mathrm{n}=31)$ entre $2000-2009$ e $1,1 \%(\mathrm{n}=1)$ entre 1990 1999. Foram identificados 14 assuntos investigados, sendo os três mais frequentes, "estado nutricional" 51,0\% ( $\mathrm{n}=50)$, "consumo alimentar" 29,5\% $(\mathrm{n}=29)$ e "antropometria" $12,2 \%$ $(\mathrm{n}=12)$, e os menos frequentes "fragilidade" $1,0 \%(\mathrm{n}=1)$, "imagem corporal" $1,0 \%(\mathrm{n}=1)$ e "rotulagem de alimentos" 1,0\% $(n=1)$. Conclusão: Observou-se maior frequência de artigos originais, com delineamento transversal, publicados no período 2010-2017 e que abordaram os assuntos estado nutricional, consumo alimentar e antropometria.

\section{Agradecimentos}

Financiamento (bolsas de mestrado e doutorado): *CNPq e **CAPES (código de financiamento 001).

\section{Profile of publications on nutrition and the elderly in Brazil: a systematic review}

\section{Abstract}

Keywords: Elderly. Aging. Nutrition. Academic communication. 